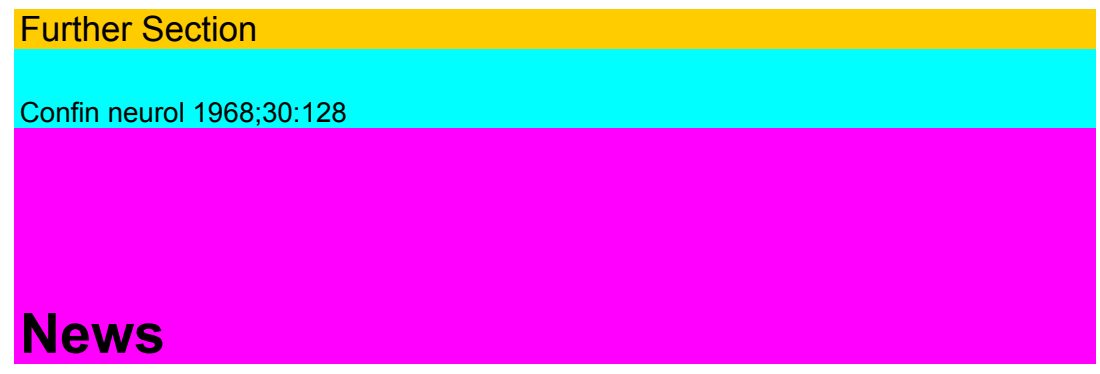

A committee of the Massachusetts General Hospital is attempting to determine pertinent features in all patients who, despite coma for over $S$ weeks, have made a useful recovery. They are eager to receive accounts of such cases reported and as yet unreported. Please communicate with:

William H. Sweet, M. D., Chief, Neurosurgical Service, Massachusetts General Hospital, Boston, Massachusetts 02114 (USA)

The International Congress on Muscle Diseases will be held on May 19-21, 1969 in Milan.

It will be grouped into various sessions: histology and histochemistry; electronic microscopy; experimental biochemistry; clinical biochemistry; electrophysiology; endocrinology; pathology; genetics and carrier state detection; clinics.

For further information apply to the congress secretaries: Drs. JV. Canal and G. Scarlato, Clinica delle Malattie Nervose e Mentali, Via F. Sforza, 35, 20122 Milano, Italy.

The Seventh International Congress of Electroencephalography and Clinical Neuro-physiology will be held in the El Cortez Hotel, in San Diego, on September 13-19, 1969. This year will be the fortieth anniversary of the first publication of the work of Hans Berger and the fortieth anniversary of the publication oiAdrian and BronVs use of coaxial electrodes to study motor unit action potentials in man. In keeping with this date, the theme of the Congress will be:

\title{
Appraisal and Perspective after Forty Years of the Functional Exploration of the Nervous System
}

The scientific program will consist of a series of didactic lectures presented by international authorities, foliowed by free Communications relating to the subject. All of the major areas will be covered, including electroencephalography, electro-myography and other electro-diagnostic techniques.

Application forms and more detailed information about the Congress can be obtained from: Richard D. Waller, M.D., Secretary, International Congress,

The Neuropsychiatric Institute at U.C.L.A., 760 Westwood Plaza, Los Angeles, Cal. 90024.

The Research Group on Head Injuries of the World Federation of Neurosurgical Societies and World Federation of Neurology and the National Institute of Neurol-ogical Diseases and Blindness of the National Institutes of Health are sponsoring a Conference on the Late Effec ts of Head Injury, to be held on March 6-7,1969, at the Shoreham Hotel, Washington, D.C. Inquiries may be directed to Dr. William F. Caveness, Building 31, Room 8A-03, National Institute of Neurological Diseases and Blindness, National Institutes of Health, Bethesda, Maryland 20014. 